\title{
On the Observation of Wild Zebrafish (Danio rerio) in India
}

\author{
Josefin Sundin, ${ }^{1,2,{ }^{*}}$ Rachael Morgan, ${ }^{2}$ Mette H. Finnøen, ${ }^{2}$ Arpita Dey, ${ }^{3}$ \\ Kripan Sarkar, ${ }^{4}$ and Fredrik Jutfelt ${ }^{2}$
}

\begin{abstract}
Zebrafish is one of the world's most widely used laboratory species, and it is utilized to answer important research questions in disparate fields such as biomedicine, genetics, developmental biology, pharmacology, toxicology, physiology, and evolution. Despite their popularity, very little is known about the biology of zebrafish in their natural habitat. This may, in part, be due to the difficulties associated with undertaking field trips to the remote areas of northern India, Nepal, and Bangladesh, which is the natural distribution range of zebrafish. Here, we present a field report describing a recent trip where we, together with local collaborators, visited several rivers in West Bengal, India, to observe wild zebrafish and their habitat. We present an overview of our observations on the biology of wild zebrafish, and the great variability of the different environments where they were found. We also include data collected on water chemistry parameters at 12 zebrafish sites, and weight data and photos of fish from these sites. We present extensive underwater videos of wild zebrafish and photographs of the sites, including video footage of courtship behavior. We show that the breeding period of wild zebrafish can be extended from the previous record of April-August to AprilOctober. In addition, we provide practical advice for future zebrafish expeditions to this rural and inaccessible area. The goals of this article are to shed some light on the ecology of wild zebrafish, and to facilitate scientists in their future research trips. We hope that by observing zebrafish in the wild, we can increase our understanding of the natural ecology of this important model organism.
\end{abstract}

Keywords: model organism, habitat, ecology, behavior, temperature, water chemistry

\section{Introduction}

$\mathbf{Z}$ EBRAFISH (DANIO RERIO) INHABIT rivers and streams in India, Nepal, and Bangladesh. They were brought into the lab and domesticated during the 1970s, and their popularity as experimental animals is still increasing. ${ }^{1}$ We currently have an in-depth understanding of the physiology, biochemistry, genetics, and behavior of the laboratory lines of zebrafish, and the scientific literature on these subjects is growing rapidly. ${ }^{1,2}$ Despite their popularity in laboratory research, a few researchers have collected experimental fish from the wild, and experiments and/or observations conducted in the wild on-site are even rarer. ${ }^{2}$ The lack of field studies and observations on wild zebrafish inevitably means that our basic knowledge of their ecology is rudimentary. ${ }^{3-5}$
To gain insight into the natural habitats and behaviors of zebrafish, we traveled to West Bengal in India in October 2016 to observe wild zebrafish and the habitats in which they can be found. During the trip, we posted a few short underwater videos on Twitter, showing groups of zebrafish recorded in the wild. The number of comments and questions that followed was overwhelming, and it exemplifies both the lack of and the need for fundamental information on the biology of wild zebrafish. Researchers around the world were requesting basic information on shoal size, temperature, occurrence of predators, schooling behavior, reproduction, overlapping generations, etc. Some of this information can be found in the scientific literature, and a review by Engeszer et al. ${ }^{2}$ provides an excellent summary of the work published up until then. Here, we aim at providing

${ }^{1}$ Department of Neuroscience, Uppsala University, Uppsala, Sweden.

${ }^{2}$ Department of Biology, Norwegian University of Science and Technology, Trondheim, Norway.

${ }^{3}$ Department of Zoology, University of North Bengal, Siliguri, India.

${ }^{4}$ Rainbow Ornamental Fish Farm, Baxipara, India.

*Current affiliation: Department of Aquatic Resources, Swedish University of Agricultural Sciences, Drottningholm, Sweden. 


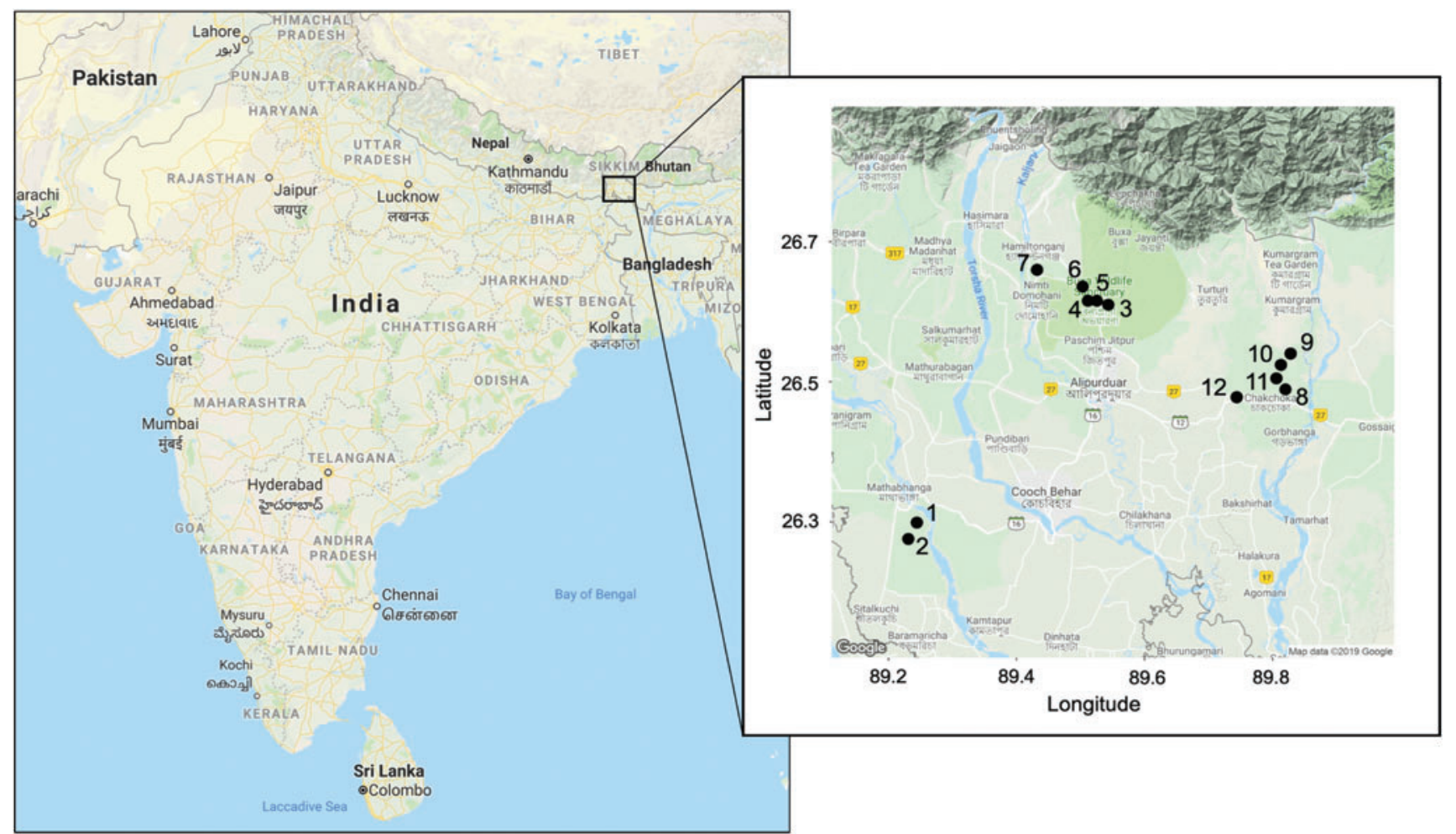

FIG. 1. Map showing the location of 12 of the sites we visited where zebrafish were photographed and water chemistry parameters were collected (additional locations mentioned in the text are not marked on this map). Map data (C2019 Google. Color images are available online.

additional observations on the biology of zebrafish in the wild. We also provide practical advice for future zebrafish expeditions to this rural and inaccessible area.

\section{The Field Trip and Zebrafish Sites}

We flew to Kolkata, India, from Norway and Sweden in October 2016. In Kolkata we visited the zebrafish lab at the Indian Institute of Science Education and Research in Mo- hanpur, a 2-h drive north of Kolkata. This lab is one of the few that does fieldwork on wild zebrafish. ${ }^{6,7}$ Although zebrafish occur in Kolkata, they can be difficult to find there. To maximize our chances of finding wild zebrafish, we therefore continued by flight from Kolkata to Bagdogra. In Bagdogra, we were picked up by our local guides and drivers, and our journey in Northern West Bengal began. We visited several rivers and streams located at a low altitude close to India's borders with Bhutan and Bangladesh, at the foothills of the

Table 1. Environmental Data from 12 Collection Sites in West Bengal, India, Sampled in October 2016

\begin{tabular}{|c|c|c|c|c|c|c|c|c|c|}
\hline Site & Coordinates & Date & Time & $\begin{array}{c}\text { Temperature } \\
\left({ }^{\circ} \mathrm{C}\right)\end{array}$ & Turbidity $_{N T U}$ & $\begin{array}{l}\text { Conductivity } \\
\left(\mu S \mathrm{~cm}^{-1}\right)\end{array}$ & $\mathrm{pCO}_{2}$ & $p H_{N B S}$ & $\begin{array}{c}\mathrm{O}_{2} \\
\left(m g L^{-1}\right)\end{array}$ \\
\hline 1 & $26^{\circ} 17^{\prime} 56^{\prime \prime} \mathrm{N}, 89^{\circ} 14^{\prime} 40^{\prime \prime} \mathrm{E}$ & October 26 & $12: 30$ & 28.9 & $5.74,5.88$ & 122.4 & & - & - \\
\hline 2 & $26^{\circ} 16^{\prime} 32^{\prime \prime} \mathrm{N}, 89^{\circ} 13^{\prime} 52^{\prime \prime} \mathrm{E}$ & October 26 & $14: 00$ & 29.7 & $6.31,16.40$ & 97.6 & - & - & - \\
\hline 3 & $26^{\circ} 36^{\prime} 36^{\prime \prime} \mathrm{N}, 89^{\circ} 32^{\prime} 00^{\prime \prime} \mathrm{E}$ & October 27 & $11: 00$ & 25.9 & $4.46,4.47$ & 62.3 & 4830 & - & - \\
\hline 4 & $26^{\circ} 36^{\prime} 56^{\prime \prime} \mathrm{N}, 89^{\circ} 31^{\prime} 32^{\prime \prime} \mathrm{E}$ & October 27 & - & 24.5 & - & - & - & - & - \\
\hline 5 & $26^{\circ} 36^{\prime} 56^{\prime \prime} \mathrm{N}, 89^{\circ} 31^{\prime} 32^{\prime \prime} \mathrm{E}$ & October 27 & - & 34.9 & $2.65,6.52$ & 101.8 & - & - & - \\
\hline 6 & $26^{\circ} 38^{\prime} 09^{\prime \prime} \mathrm{N}, 89^{\circ} 30^{\prime} 12^{\prime \prime} \mathrm{E}$ & October 27 & $13: 30$ & 30.1 & $2.03,2.62$ & 155.8 & 4450 & - & 一 \\
\hline 7 & $26^{\circ} 39^{\prime} 35^{\prime \prime} \mathrm{N}, 89^{\circ} 25^{\prime} 56^{\prime \prime} \mathrm{E}$ & October 27 & $14: 30$ & 27.7 & $3.77,5.64$ & 81.3 & 4730 & - & - \\
\hline 8 & $26^{\circ} 29^{\prime} 21^{\prime \prime} \mathrm{N}, 89^{\circ} 49^{\prime} 18^{\prime \prime} \mathrm{E}$ & October 28 & $10: 40$ & 28.0 & $6.63,17.90$ & 117.1 & 4760 & 7.2 & 8.62 \\
\hline 9 & $26^{\circ} 31^{\prime} 49^{\prime \prime} \mathrm{N}, 89^{\circ} 49^{\prime} 39^{\prime \prime} \mathrm{E}$ & October 28 & $12: 15$ & 27.6 & $2.92,3.81$ & 134.7 & 4700 & 7.4 & 8.86 \\
\hline 10 & $26^{\circ} 31^{\prime} 27^{\prime \prime} \mathrm{N}, 89^{\circ} 48^{\prime} 47^{\prime \prime} \mathrm{E}$ & October 28 & $12: 30$ & 27.0 & $11.70,12.80$ & 151.6 & 4780 & 7.1 & 4.25 \\
\hline 11 & $26^{\circ} 30^{\prime} 18^{\prime \prime} \mathrm{N}, 89^{\circ} 48^{\prime} 21^{\prime \prime} \mathrm{E}$ & October 28 & $13: 00$ & 27.7 & $4.60,4.75$ & 155.6 & 4730 & 7.6 & 8.92 \\
\hline 12 & $26^{\circ} 28^{\prime} 41^{\prime \prime} \mathrm{N}, 89^{\circ} 44^{\prime} 38^{\prime \prime} \mathrm{E}$ & October 28 & $15: 30$ & 28.5 & $19.30,20.90$ & 218.0 & - & 7.3 & 3.92 \\
\hline
\end{tabular}

Turbidity was measured in duplicate, and data for both samples are reported. Note that these data have previously been presented in Morgan et al..$^{8}$ 
FIG. 2. Histograms showing weight (grams) of zebrafish at each of the 12 sites where fish were collected and weighed, ordered by medians (weight data pooled from fish measured outdoors on-site and from $\mathrm{CT}_{\max }$ experiment). Sample size and site temperatures for each site are given to the right. Color images are available online.

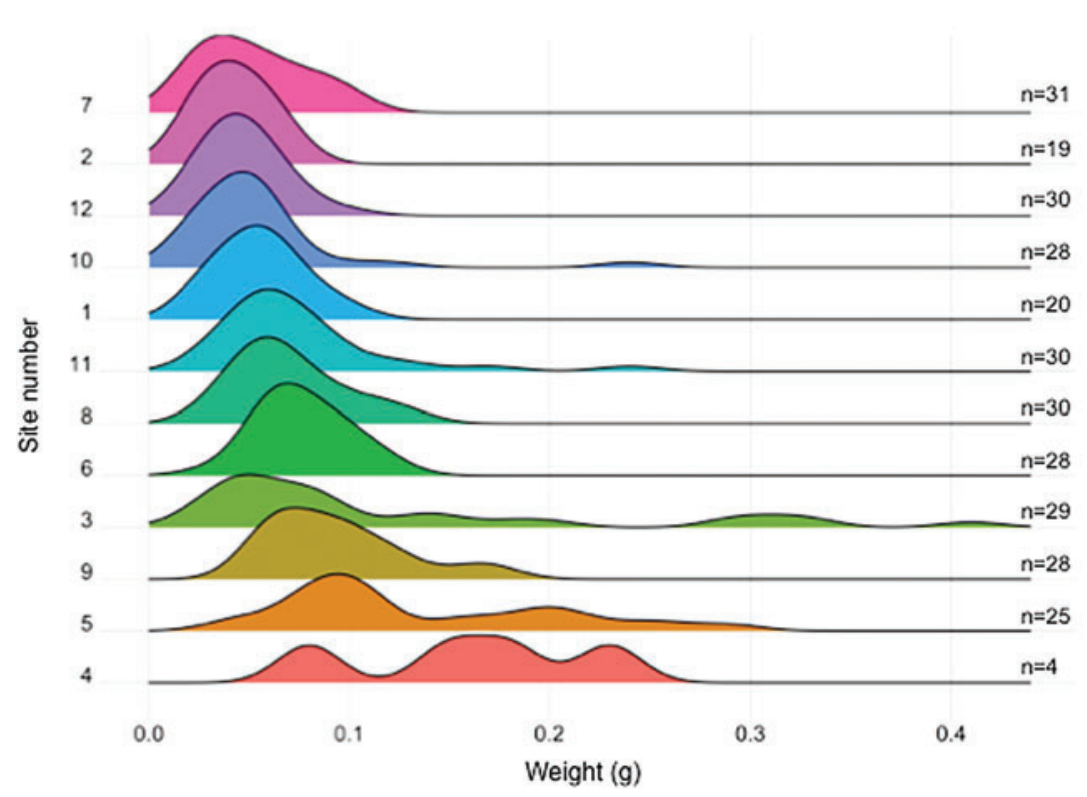

Site temperature $27.7^{\circ} \mathrm{C}$

$29.7^{\circ} \mathrm{C}$

$28.5^{\circ} \mathrm{C}$

$27.0^{\circ} \mathrm{C}$

$28.9^{\circ} \mathrm{C}$

$27.7^{\circ} \mathrm{C}$

$28.0^{\circ} \mathrm{C}$

$30.1^{\circ} \mathrm{C}$

$25.9^{\circ} \mathrm{C}$

$27.6^{\circ} \mathrm{C}$

$34.9^{\circ} \mathrm{C}$

$24.5^{\circ} \mathrm{C}$
Himalayas (Fig. 1). We observed the general behavior of the zebrafish, and photographs were taken to illustrate the topography and vegetation coverage. Where possible, underwater video footage was taken of the fish at the field sites (https://vimeo.com/356755335, https://youtu.be/ mDR0a78GXig an additional underwater video is available on request). At 12 of the locations (Fig. 1), zebrafish were collected by local fishermen using small seine nets (see section below on Zebrafish Characteristics). We also measured water chemistry parameters at these 12 sites (temperature, turbidity, conductivity, $p \mathrm{CO}_{2}, \mathrm{pH}$, and $\mathrm{O}_{2}$, Table 1).

\section{Zebrafish Characteristics}

A randomly selected subset of the fish collected at 11 of the 12 sites ( $n=19-20$ per site) were photographed (outdoors) on millimeter paper for descriptive purposes and weighed (to the nearest $0.01 \mathrm{~g}$ ). Fish weight differed between the sites (analysis of variance: $\mathrm{F}_{10,206}=17.42, p<0.001$ ), with the largest fish being found at site 5 , which was also the warmest of the 12 sites with a temperature of $34.9^{\circ} \mathrm{C}$ (Table 1 , excluding a small pond with a temperature of $35.5^{\circ} \mathrm{C}$ from where fish were not sampled [not included in the 12 sites], see section below on zebrafish habitats). The weight range across sites was $0.02-0.29 \mathrm{~g}$, mean: $0.07 \pm 0.04 \mathrm{~g}$ (SD). We observed no obvious differences in morphology between the sites; however, this was not quantified. The photographs of the zebrafish are available on Figshare (doi: 10.6084/ m9.figshare.8148776), and we encourage researchers to make use of those images (high-resolution raw-files can be obtained on request). Data on weights can be found in the Supplementary Data. In addition, using fish from 10 of the sites, we performed an on-site experiment testing the upper thermal tolerance $\left(\mathrm{CT}_{\max }\right)$ of wild zebrafish ${ }^{8}$ (the site numbers $1-12$ used here correspond to sites 1-12 in Morgan et al. ${ }^{8}$ ). On completion of the $\mathrm{CT}_{\max }$ test (for results, see Morgan et $a .^{8}$ ), the fish were anesthetized, photographed (indoors) on millimeter paper for descriptive pur- poses, and weighed (to the nearest $0.01 \mathrm{~g})(n=4-11$ per site). Those photographs are also available on Figshare (doi: 10.6084/m9.figshare.8148776), and data on weights are included in the Supplementary Data. The majority of the fish at all sites appeared to be young-of-the-year, with only a few larger fish found at a subset of the sites (Fig. 2), pooling the weight data from the fish measured outdoors on-site and from the $\mathrm{CT}_{\max }$ experiment (small fish could not be included in the $\mathrm{CT}_{\max }$ test, as they would swim

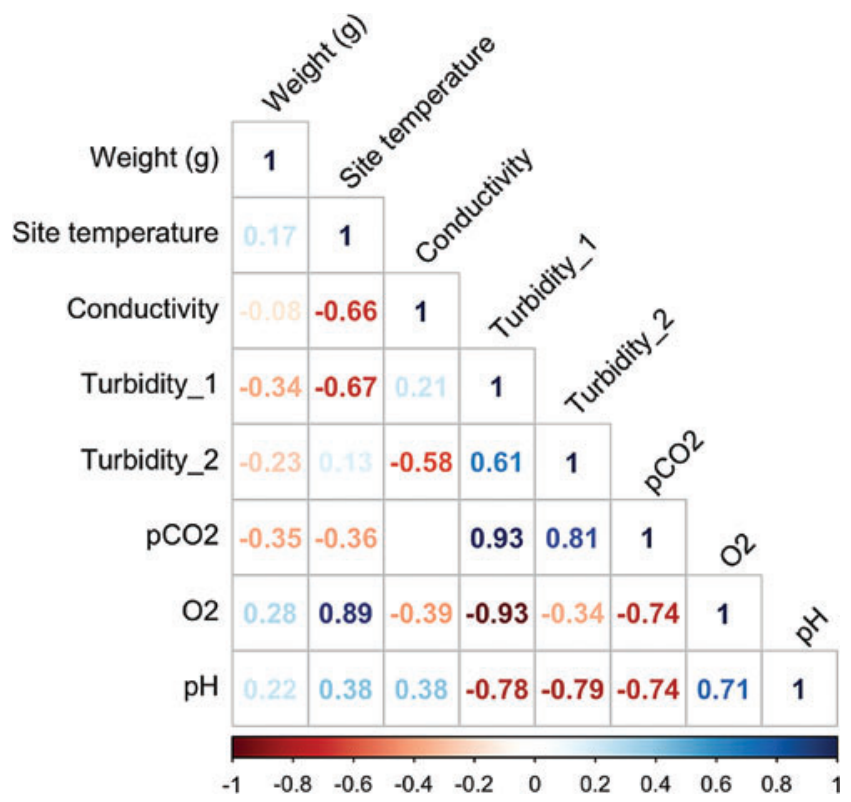

FIG. 3. Correlation matrix between fish weight and water chemistry parameters. Warm colors (red) indicate a negative correlation, and cool colors (blue) indicate a positive correlation. The darker the color the stronger the correlation. Color images are available online. 

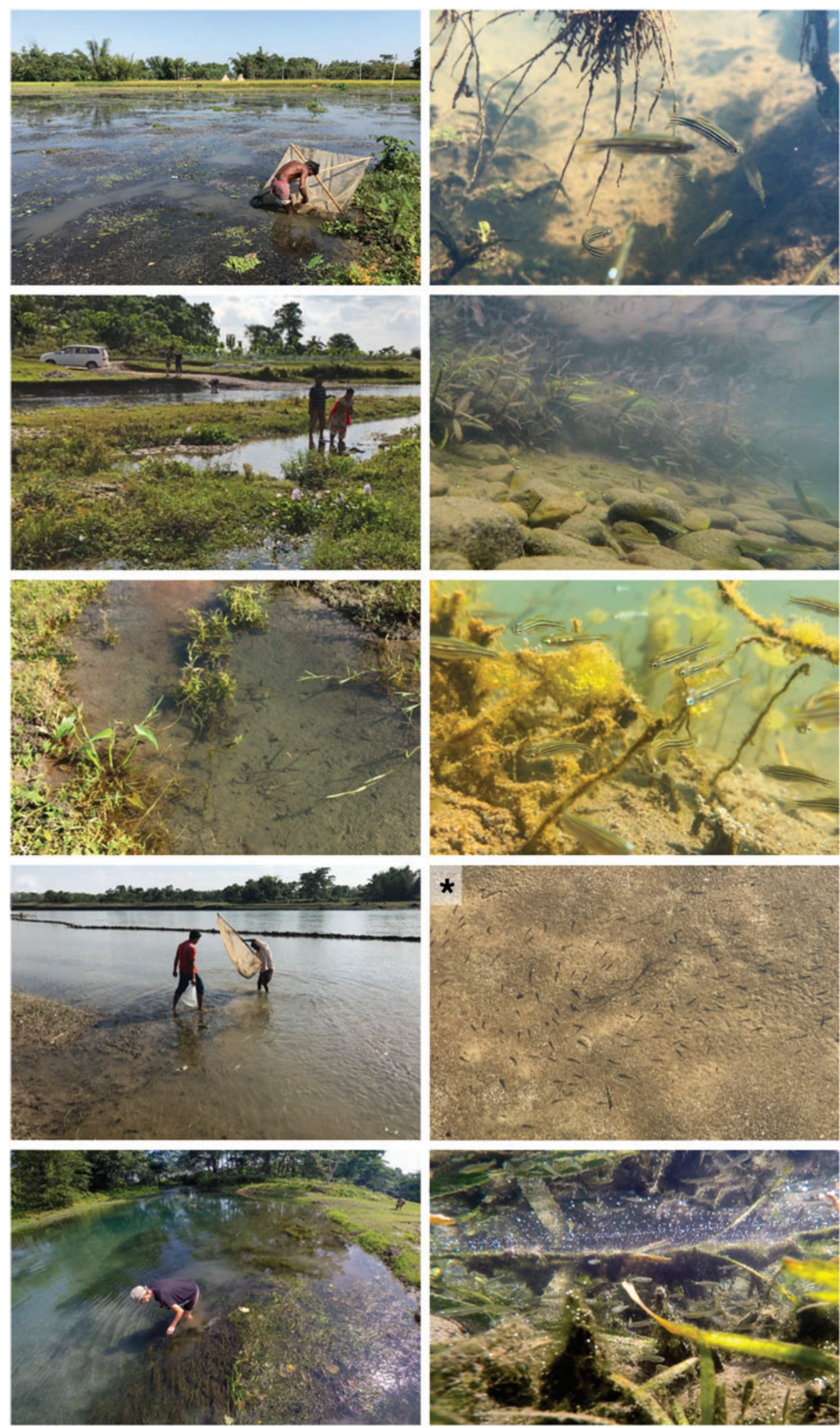

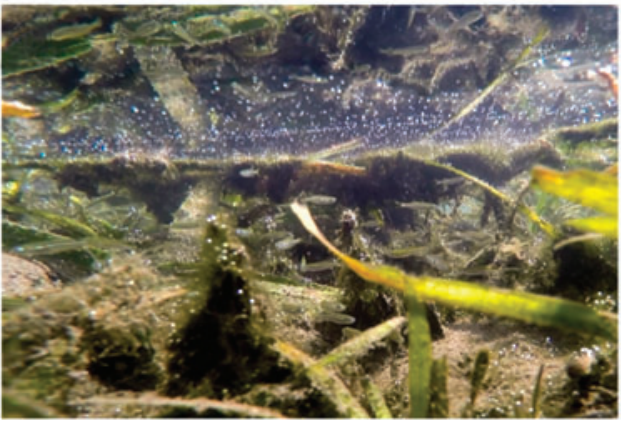

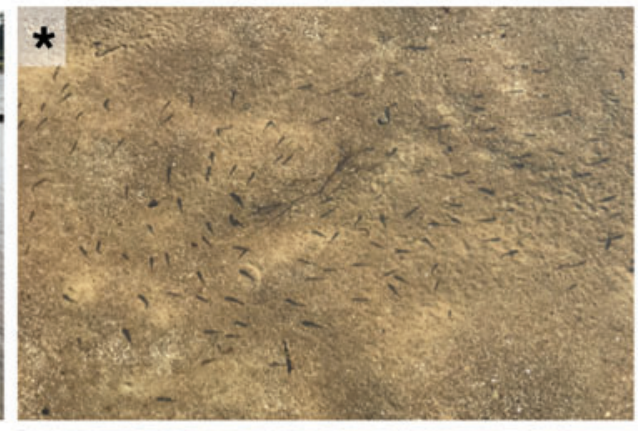

FIG. 4. Photographs of some of the zebrafish sites showing the variety in environments in which they live. Right hand panels show underwater view of the corresponding panel to the left (except for * where the water was too shallow for underwater photography). Color images are available online. 
through the mesh in the experimental setup, see Morgan et al. ${ }^{8,9}$ for details). These fish could be indicative of multiple spawning events within the spawning season. However, the fact that we found very few large and mature zebrafish suggests that many may not survive more than one breeding season in the wild. It is also possible that there is a spatial separation between adults and juveniles, but our guides and local fish experts were not aware of other sites with larger zebrafish adults. There were no strong correlations between fish weight and the measured water chemistry parameters; however, several of the water chemistry parameters were correlated (Fig. 3).

\section{Zebrafish Habitats}

The habitats where we found zebrafish ranged from open riverbanks with clear and rapidly flowing water, dense forests with turbid and slow-moving water, and stagnant ponds with dense plant growth, highlighting the variety of environments where zebrafish can survive and thrive (Fig. 4). One of the sites was a wide and shallow stream with slow moving water (site 1, Fig. 4A, B). The surroundings were open, grazed grasslands. Zebrafish were found in abundance, swimming in shoals by the edges of the pond among the dense underwater vegetation (Fig. 4A, B). We also observed zebrafish in deeper streams with stronger current and less underwater vegetation (site 11, Fig. 4C-F). In this gravel-dominated stream, they were found both along the edge of the stream in fast moving water with sparse vegetation (Fig. 4D), and on the opposite side of the stream in small ponds where the water was calmer and shallower (Fig. 4E, F). The most extreme temperature where we found zebrafish was at $35.3^{\circ} \mathrm{C}$ (next to site 2). Here, the zebrafish were trapped in a shallow pond on a sand bank (Fig. 4H), a few meters away from a large river (site 2, Fig. 4G). This small pond had no vegetation and was fully sun exposed, hence the high temperature. The zebrafish in the pond were swimming together in one shoal consisting of $\sim 100$ individuals. Their swimming behavior appeared coordinated and schooling-like (https://vimeo.com/356755335\#t=6m33s). No fish were collected from this pond. In an adjacent, connected pond, the water was even warmer, $37.2^{\circ} \mathrm{C}$, but this area seemed to be avoided by the fish as we observed no fish here. In the large river at this location (site 2, Fig. 4G), we found zebrafish by the edges of the river in the sparse grass vegetation. The coldest site where we found zebrafish was near a natural well, with cold spring water, at a temperature of $24.5^{\circ} \mathrm{C}$ ( site 4 , https://vimeo.com $/ 356755335 \# \mathrm{t}=$ $11 \mathrm{~m} 3 \mathrm{~s})$. They were also found in a clear, quite deep and large stream where the underwater vegetation was dominated by eelgrass (site 8, Fig. 4I, J, https://vimeo.com/ $356755335 \# \mathrm{t}=12 \mathrm{~m} 33 \mathrm{~s}$ ). Again, they were found by the shallow edges of the stream, in the dense eelgrass vegetation. At this site, we also found pipefish (pregnant male rainbow belly pipefish, Microphis deocata), which could be indicative of high water quality (anecdotal information by local fish experts). All of the sites described earlier were characterized by open surroundings, but we also found zebrafish in streams running through forests. For example, at one site, they were found in a dense bamboo forest (site 9, Fig. 5). Although we found zebrafish at most sites that our local guides showed us, we also visited sites with seemingly suitable habitats where we could not find zebrafish (Fig. 6, https://vimeo.com/356755335\#t=7m42s).

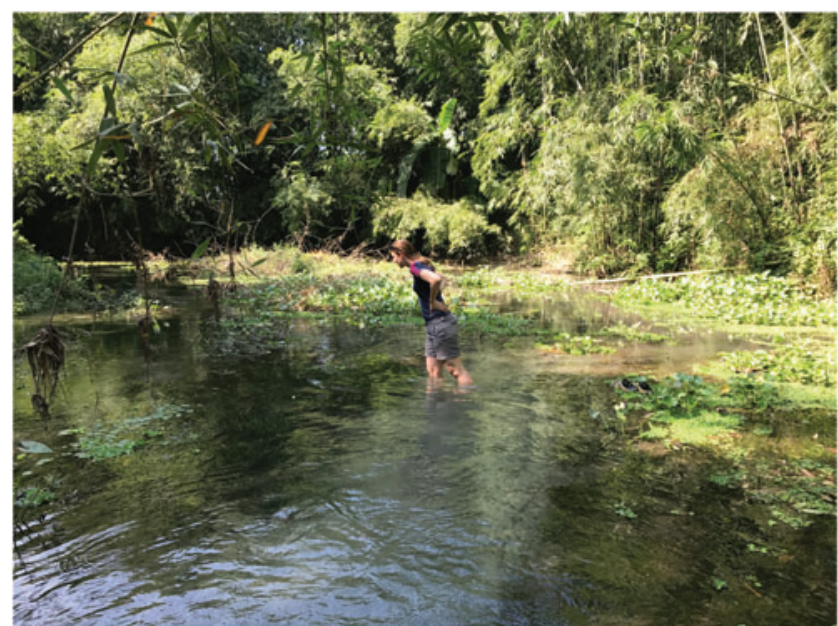

FIG. 5. Stream running though a dense bamboo forest (site 9) where zebrafish were found. Photo reproduced with permission. Color images are available online.

\section{Zebrafish Behaviors Observed}

\section{Shoaling and group size}

At one location, not included in the sites numbered 1-12, we observed zebrafish at extremely high densities in very large shoals. The water body in which this observation was made did not even measure $1 \mathrm{~m}^{2}$ and contained potentially thousands of zebrafish in one shoal (Fig. 7, https://vimeo.com/ $356755335 \# t=6 \mathrm{~m} 58 \mathrm{~s})$. It is unclear whether the fish occupied themselves in this water body intentionally, or whether they were trapped there, since this pond was located at the drain from an upper pond. Since this location was not included in our 12 sites, we did not take any water chemistry measurements and we did not photograph the fish, but our observations, nonetheless, show that zebrafish can aggregate in very large shoals and live at extremely high densities. This observation extends our knowledge on maximum shoal

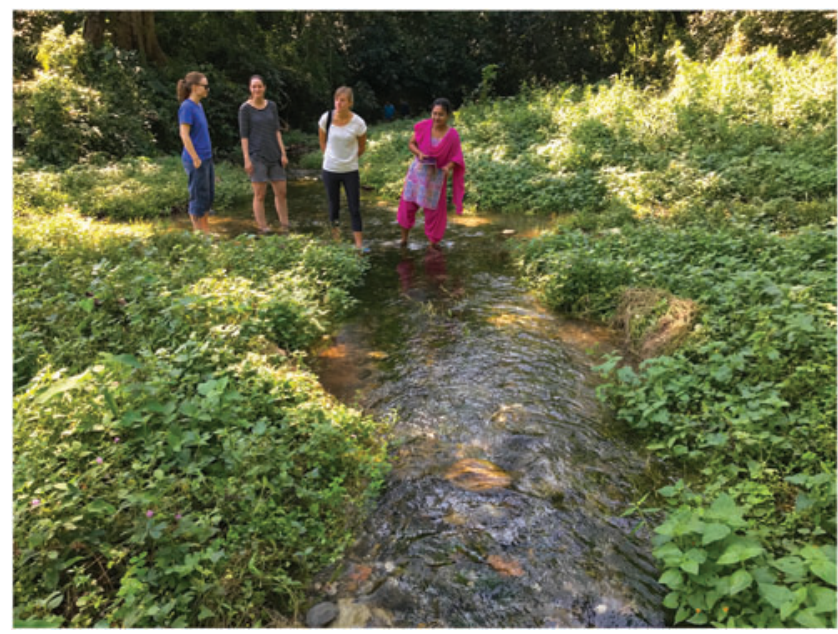

FIG. 6. Stream with seemingly suitable habitats where no zebrafish were found (https://vimeo.com/356755335\#t= $7 \mathrm{~m} 42 \mathrm{~s}$ ). Photo reproduced with permission. Color images are available online. 

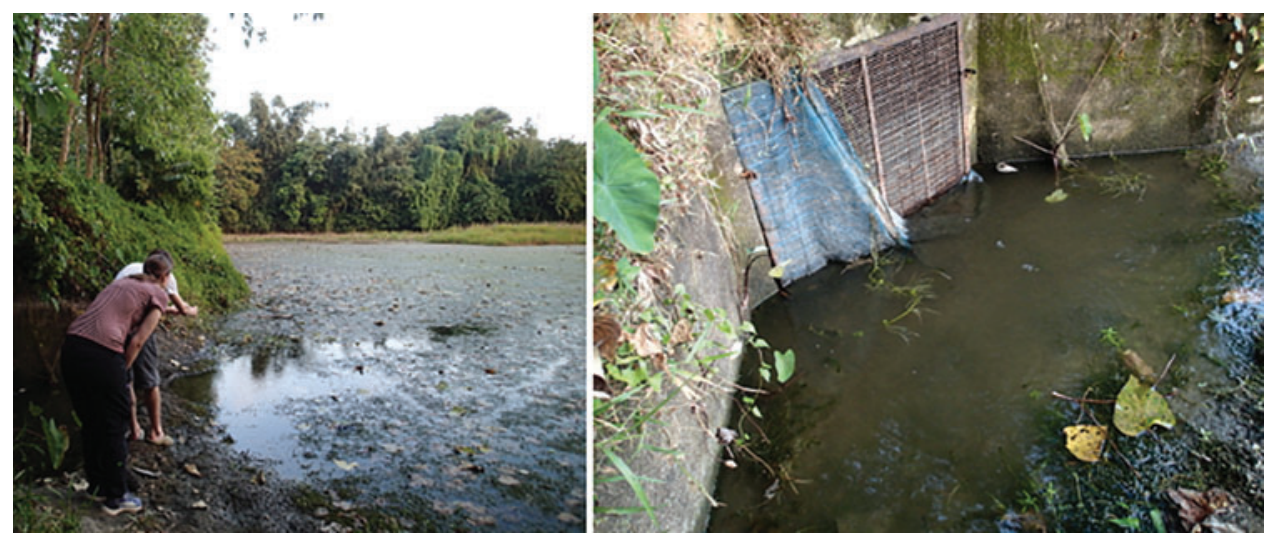

FIG. 7. The pond and surrounding area where zebrafish were found at an extremely high density, with potentially thousands of fish in one shoal (https://vimeo.com/35675533 $5 \# \mathrm{t}=6 \mathrm{~m} 58 \mathrm{~s})$. Color images are available online.

size, as previous papers report that zebrafish school in groups of up to 300 individuals. $^{8}$

\section{Mating behavior}

The breeding season of wild zebrafish has previously been reported to occur between April and August, ${ }^{1,2}$ and it has also been stated that the spawning behavior has only been described from laboratory settings. ${ }^{2} \mathrm{We}$, however, observed mating behavior at one of the sites we visited, meaning that the previous noted breeding period can be extended at least to October. We observed courtship rather than spawning, and this behavior was also video recorded (https://vimeo.com/356755335\#t=8m42s). The courtship behavior was observed over muddy substrate in very shallow water $(3-10 \mathrm{~cm})$ among the dense vegetation by the edge of a stream running through a grazed area with livestock (site 3, Fig. 8). The temperature in this area of the stream was warmer, with a temperature of $27.5^{\circ} \mathrm{C}$, compared with $25.9^{\circ} \mathrm{C}$ in the main stream (Table 1 , site 3 ).

\section{Practical Advice}

Zebrafish locations can vary from season to season and year to year, depending on water availability. This implies that even if a site was good one season/year, it does not necessarily mean that it will be so in the future. In fact, the entire site might not even be present during following seasons/years (anecdotal information from local fish experts). The best way to counteract any such issues is to have a re- liable local contact. Our on-site guides provided us with all such necessary information, as they had extensive knowledge about the area, local fishermen, current conditions, and the species of fish in the area. In addition, we were in contact with a supplier of wild fish for the ornamental industry who arranged practical matters, such as drivers, cars, hotel bookings, etc. To make these arrangements they needed basic information, such as budget for hotels and ground logistics (e.g., cars and drivers), and amount of equipment and luggage to plan vehicle size (a nontrivial detail!). For budget purposes, it is good to take into consideration that costs for travel (road, air, any other), accommodation in hotels, and all meals during the entire length of the travel for the guides, local fishermen, etc. is most likely expected to be covered by the visiting researchers. In addition, there might be extra costs for food and accommodation for local assistants who join the fieldtrip along the way and who had not planned to join from the beginning. Overall, it is important to be flexible in terms of organization (further discussed below).

We visited many rural areas, and the hotel standard in the nearby villages/towns was highly variable. For example, the mattresses were sometimes made of Styrofoam, which might come across as unusual to sleep on if one is used to softer mattress materials. When we visited the Buxa Tiger Reserve, we stayed at the Buxa Wildlife Sanctuary. The standard of the huts was good, but since the walls were made of bamboo they were not impervious and we had curious rats visiting our rooms and bags. The local cars were large and robust
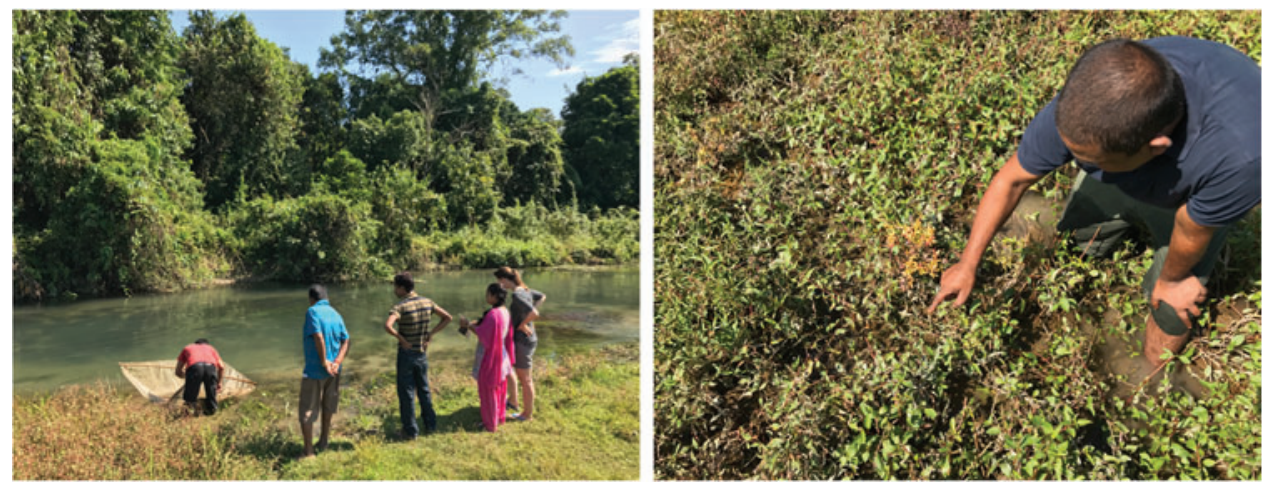

FIG. 8. The site where courtship behavior was observed in very shallow water among the dense vegetation (site 3, https://vimeo.com/ $356755335 \# \mathrm{t}=8 \mathrm{~m} 42 \mathrm{~s})$. Color images are available online. 
FIG. 9. Tourists and/or researchers are a rare sight in the rural areas of West Bengal, which inevitably leads to attention from the local inhabitants within walking and biking distance. The locals were friendly and very curios. Landowners would sometimes offer tea and serve it by the zebrafish pond if time was too scarce for a proper tea break inside. Photos reproduced with permission. Color images are available online.
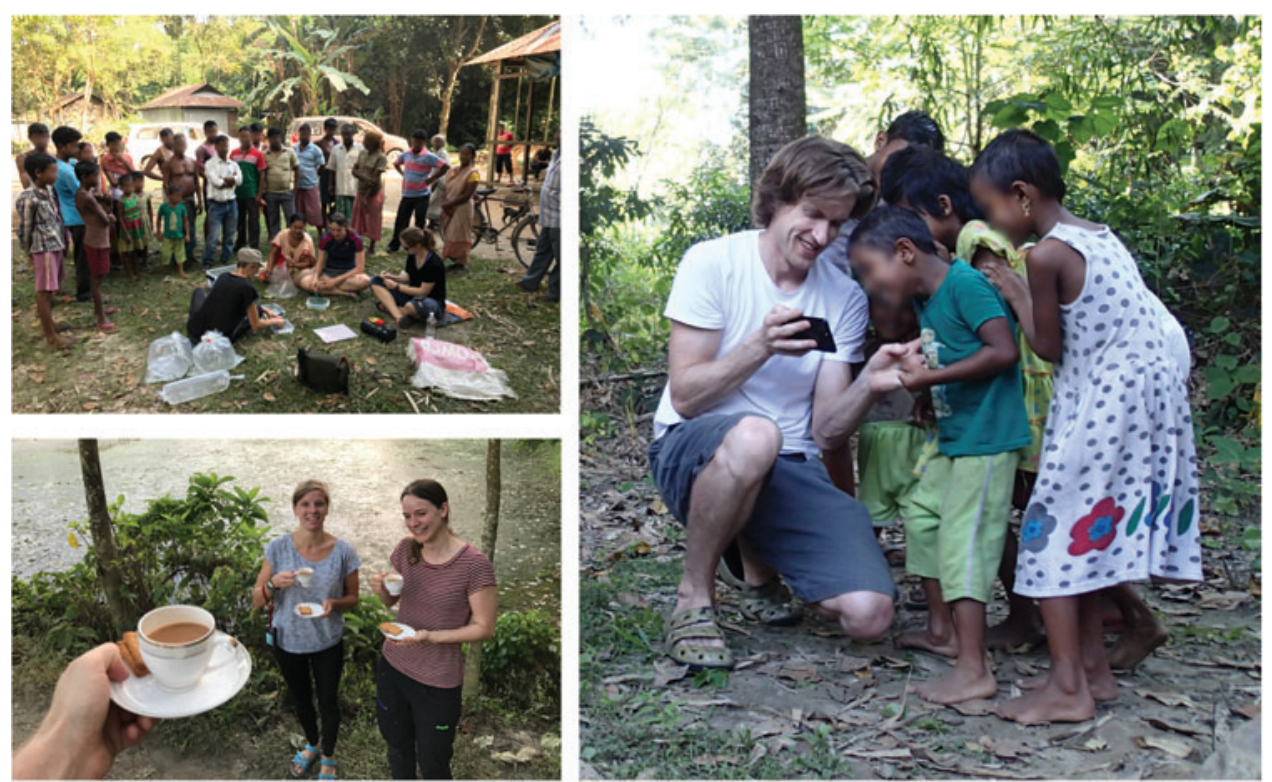

and could hence fit our equipment and access all areas. Renting a car, or organizing it in another way, usually means the car comes with a driver. This arrangement might be unusual to some, but it is practical and highly recommended. The road standard is sometimes poor, and the traffic can be very challenging on the countryside (e.g., a mix of all kinds of vehicles, cows, dogs, people biking against the traffic on the motorway, driving in four lanes on two-lane roads, etc.). Local skills in driving under such circumstances are needed for everyone's safety. If multiple drivers and cars are used (as in our case), it is highly recommended to ensure an English-speaking driver is in the car where the researchers are traveling. This too is a nontrivial matter, since it cannot be foreseen when urgent questions to the driver might arise (e.g., urgent requests for access to a bathroom).

The local inhabitants who we met during the fieldtrip were friendly and curious. Tourists and/or scientists is a very rare sight in these areas, and each stop inevitably drew the attention of anyone within walking/biking distance (Fig. 9). In general, it is important to be flexible with time and organization. Allocate a decent amount of time for breakfast and lunch. Be prepared for sudden changes of plans regarding when to leave in the morning, what locations to visit and in which order, when to finish for the day, how many local helpers and fishermen are joining for the day, etc. Remember to bring food, water, hygiene products, etc. to last the entire length of a day. When planning the trip, it is also important to make sure that there are no major local holidays. We had originally planned our trip to commence in the beginning of October, but due to the festival called Dusshera (in October 10-11) we had to delay the trip as the festival is a major holiday that would have made travel difficult.

If the visiting researchers plan to sample fish and bring them out of the country, it is of vital importance to be aware of permit requirements for sampling wild populations. The Indian government has passed a Biodiversity Act dealing with bringing samples abroad, especially involving foreign funds or collaboration with foreign universities. Information about the Act can be found at the Ministry of Environment and Forests.

\section{Acknowledgments}

The authors extend their thanks to Mikael Håkansson and Jonathan Rao and colleagues for logistical support. They are grateful to the local fishermen in India for their assistance in collecting the zebrafish, and to their guides in India for taking them to the zebrafish sites and sharing their zebrafish knowledge with them. Capture and handling of zebrafish was performed by local fish experts and scientists, covered under permit number 1932802178001, obtained from the Directorate of Fisheries, Government of West Bengal. In accordance with the Indian government's Biodiversity Act, no fish/biological samples were brought out of India by the researchers. The authors thank two anonymous reviewers for valuable comments.

\section{Funding Information}

This work was funded by the Research Council of Norway (F.J.: 262942) and the Swedish Research Council Formas (J.S.: 2013-947).

\section{Supplementary Material}

Supplementary Data

\section{References}

1. Meyers JR. Zebrafish: development of a vertebrate model organism. Curr Protoc Essent Lab Tech 2018;16:e19.

2. Engeszer RE, Patterson LB, Rao AA, Parichy DM. Zebrafish in the wild: a review of natural history and new notes from the field. Zebrafish 2007;4:21-40. 
3. McClure MM, McIntyre PB, McCune AR. Notes on the natural diet and habitat of eight danionin fishes, including the zebrafish Danio rerio. J Fish Biol 2006;69:553-570.

4. Spence R, Fatema MK, Reichard M, Huq KA, Wahab MA, Ahmed ZF, et al. The distribution and habitat preferences of the zebrafish in Bangladesh. J Fish Biol 2006;69:1435-1448.

5. Raja M, Raja RK, Perumal P. Zebrafish in the wild: microhabitat use by zebrafish Danio rerio (Hamilton, 1822) from Karala river of Jalpaiguri district, Northern Bengal, India. Fish Aqua J 2016;7:179.

6. Roy T, Bhat A. Population, sex and body size: determinants of behavioural variations and behavioural correlations among wild zebrafish Danio rerio. Roy Soc Open Sci 2018;5:170978.

7. Suriyampola PS, Shelton DS, Shukla R, Roy T, Bhat A, Martins EP. Zebrafish social behavior in the wild. Zebrafish 2016;13:1-8.
8. Morgan R, Sundin J, Finnøen M, Dresler G, Martínez Vendrell M, Dey A, et al. Are model organisms representative for climate change research? Testing thermal tolerance in wild and laboratory zebrafish populations. Conserv Physiol 2019;7:coz036.

9. Morgan R, Finnøen MH, Jutfelt F. CTmax is repeatable and doesn't reduce growth in zebrafish. Sci Rep 2018;8: 7099.

Address correspondence to: Josefin Sundin, PhD Department of Aquatic Resources Swedish University of Agricultural Sciences SE-178 93 Drottningholm Sweden

E-mail: josefin@teamsundin.se; josefin.sundin@slu.se 